the two proportions was highly significant. We also compared BV present in LSIL group with HSIL group. BV was present in $29 \%$ cases in LSIL group compared to $45 \%$ in HSIL group $(\mathrm{P}=0.03)$. The difference between the two proportions was significant.

Conclusion The presence of BV was significantly higher in SIL group and was associated with the severity of SIL. The presence of BV should not deter a diagnosis of SIL but trigger a meticulous search for abnormal cells.

\section{P2.005 GIANT CONDYLOMA ACUMINATA OF BUSCHKE AND LOWENSTEIN TREATED SUCCESSFULLY SURGICALLY}

doi:10.1136/sextrans-2013-051184.0270

N Puri, A Talwar. Punjab Health Systems Corporation, Ferozepur, India

Introduction The Buschke Lowenstein tumour is an extremely rare, slow-growing, locally destructive, cauliflower-like mass, also known as giant condyloma acuminata.

Case Report: We report a case of a 42 year old male who presented to the department of surgery with perineal tumour since two years. The mass was painless initially but later became painful. On local examination, the ano perineal region of the patient was completely occupied by a cauliflower like tumour with multiple fistulae. After histopathological confirmation, the tumour was removed surgically, as it was resistant to medical treatment. Radical surgery was attempted. The tumour was found to be very vascular and deeply infiltrating. Wide local resection of the perianal tissue was performed Discussion Histopathology of BLT shows blunt-shaped masses of tumour project deeply into the dermis and contiguous structures. The tumour cells have little evidence of atypia and are not found inside blood vessels or lymphatics. Individual keratinocytes may show keratinization, but no horn pearls are seen. Lymphohistiocytic inflammation is usually present.

Conclusion Troublesome recurrences of BLT occur frequently and a propensity for infection and fistula formation is common. Regardless of the size and origin of BLTs, gaining early control of the disease using wide, radical surgical excision provides the best overall rate of survival.

\section{P2.006 EVALUATION OF A MODIFIED CD4 COUNT METHOD FOR HIV MONITORING}

doi:10.1136/sextrans-2013-051184.0271

E Elharti, H Lembrabet, H Abadi, H Oumzil, R El Aouad. National Institut of Health, Rabat, Morocco

Introduction The measurement of CD4 count for HIV-infected individuals relies on flow cytometry methods. The standard one is a single platform technology, which uses $50 \mu \mathrm{l}$ of samples and $10 \mu \mathrm{l}$ of monoclonal antibodies. To reduce the CD4 count cost, we propose to asses a modified method based on reducing the sample and monoclonal antibodies volumes.

Methods Between February and May 2011, we have tested 90 samples of HIV-infected persons by the standard method i.e using $50 \mu \mathrm{l}$ of anticoagluated blood and $10 \mu \mathrm{l}$ of monoclonal antibodies (CD3FITC/CD4PE/CD45PerCP, Becton-Dickinson) and by the modified method i.e using $20 \mu \mathrm{l}$ of anticoagluated blood and $2 \mu \mathrm{l}$ of monocolonal antibodies (CD3FITC/CD4PE/CD45PerCP, BectonDickinson), in our laboratory. The \% of CD4 as well as the absolute count (TrueCount, Becton-Dickinson) was determined for both methods by using Cellquest-Pro on FacsCalibur (Becton-Dickinson). Linear regression and Bland and Altman analysis were performed to assess correlation and agreement between both methods.

Results When analysing the whole sample, the modified method showed a strong correlation with the standard method, $r=0.99$ for CD4 count percent. Bland and Altman analysis revealed a mean bias of $-0.1 \%$ (Limit of agreement: $-3.0,2.8$ ). Regarding the absolute count of CD4, $r$ was 0.99 and the mean bias was 9 cells/ $\mu$ l (LOA:$64.8,82.5)$. When the statistical analysis is performed for the strata of $\mathrm{CD} 4 \leq 350$, the $\mathrm{r}$ was 0.98 , and the mean bias was -1 cell $/ \mu \mathrm{l}$ (LOA: -44.1, 42.2).

Conclusion The modified method based on reducing blood and antibodies volumes showed similar results to the standard method. This low cost method may be an interesting alternative method to measure CD4 count in developing countries.

\section{P2.007 GENETIC RISK OF DNA REPAIR GENE POLYMORPHISMS IN HIGH- RISK HPV ASSOCIATED CERVICAL CARCINOGENESIS}

doi:10.1136/sextrans-2013-051184.0272

D Bajpai, A Banerjee, S Pathak, S Jain, N Singh. All India Institute of Medical Sciences, New Delhi, India

Background Cervical cancer is the second most common cancer in women worldwide. A large number of young sexually active women get infected by human papillomavirus (HPV) but only a small fraction of them have persistent infection and develop cervical cancer pointing to co-factors including host genetics that might play a role in outcome of the HPV infection. This study was designed to examine the polymorphisms associated with four DNA repair genes, viz., XRCC1 (Arg194Trp, Arg399Gln and Arg280His), ERCC1 Asp118Asp, ERCC2 Lys751Gln and ERCC4 Arg415Gln and investigate their role as susceptibility markers for cervical precancer (LSIL $\&$ HSIL) and cancer.

Methods The cases comprised 105 patients: 65 cervical squamous cell carcinomas (SCCs), and 40 squamous intraepithelial lesions (SILs). 65 healthy women were recruited as the controls. Genotypes were determined by PCR-RFLP and DNA sequencing techniques.

Results Our data showed a positive association between the polymorphisms of codons 194 ( $\mathrm{p}=0.001, \mathrm{OR}=22.4,95 \% \mathrm{CI}=9.15$ 55.03), $280(\mathrm{p}=0.001, \mathrm{OR}=20.04,95 \% \mathrm{CI}=8.4-47.5)$ and 399 $(\mathrm{p}=0.001, \mathrm{OR}=11.11,95 \% \mathrm{CI}=4.98-24.78)$ and cervical cancer. SIL patients also showed a significant association with codon 194 $(\mathrm{p}=0.001, \mathrm{OR}=7.56,95 \% \mathrm{CI}=3.42-16.70)$ and $280(\mathrm{p}=0.015$, $\mathrm{OR}=3.05,95 \% \mathrm{CI}=1.35-6.88)$ but not with $399(\mathrm{p}=0.142)$. Positive correlation was also found in ERCC4 Gln415GIn in both SCCs and SILs $(\mathrm{p}=0.001, \mathrm{OR}=5.45,95 \%=3.19-9.29$ and $\mathrm{p}=0.001$, $\mathrm{OR}=2.76,95 \%=1.55-4.91$, respectively). For ERCC2 Gln751Gln the association was significant for SCCs ( $p=0.010, \mathrm{OR}=1.44$, $95 \%=0.86-2.14)$ but not for SILs $(p=0.088)$. However the risk for cervical precancer and cancer did not appear to differ significantly amongst individuals featuring the ERCC1 Asp118Asp genotype ( $p=0.594$ and 0.080 , respectively).

Conclusion We analysed the association between XRCC1, ERCC4 ERCC2 and ERCC1 polymorphisms and the individual susceptibility to develop cervical precancer and cancer. We attempt to contribute to the discovery of which biomarkers of DNA repair are useful for screening this high-risk population for primary preventing and early detection of cervical cancer.

\section{P2.008 MISTAKEN CASE OF CHILD ABUSE: A CASE REPORT}

doi:10.1136/sextrans-2013-051184.0273

S Sood, R Verma, A Mukherjee, N Mahajan, B K Das, A Kapil, S Gupta, V K Sharma. All India Institute of Medical Sciences, New Delhi, India

Introduction The diagnosis of child abuse is based on a combination of child's history, physical findings, and when appropriate, laboratory and other tests. Overall, the diagnosis is often complicated but suspicion should always be followed by further investigations. Formulating a conclusion and reaching a diagnosis of child 